\title{
TRABAJO U HONOR \\ El trabajo femenino \\ en la economía contemporánea
}

France Caillavet

Los comportamientos generalmente observados en la España contemporánea frente al trabajo femenino - mercantil o no mercantil- remiten en muchos casos al «doble lenguaje» (double bind). El trabajo femenino en el sector doméstico no se percibe como trabajo profesional. La actividad en el sector mercantil es socialmente sospechosa; sin embargo, se revela oportuna para la economía en su conjunto.

Este artículo analiza las normas sociales que rigen la actividad femenina, así como el partido económico sacado de aquélla. Pretende revelar las contradicciones aparentes de estas dos lecturas del tejido social.

\section{EL TRABAJO MERCANTIL O EL HONOR}

El concepto de trabajo en el sistema del honor

Parece difícil determinar qué criterio — clase o género (gender)— predomina en el sistema del honor. Este instaura el lugar adecuado del individuo en la sociedad, pero esta ubicación está definida previamente según el medio de origen y el sexo. 
Pitt-Rivers ${ }^{1}$ sitúa la especifidad del código de honor mediterráneo, en oposición con aquellos vigentes en Europa septentrional, en la noción de honor colectivo (honra): los varones son responsables de las mujeres de la familia, cuyo honor está asociado con su pureza sexual; el honor de los varones, en cambio, depende en gran medida de la manera en la cual cumplen con esta responsabilidad. En realidad, estas normas expresan la mirada de una sociedad patriarcal sobre el individuo.

El sistema del honor parece ubicarse bajo el signo de la dualidad, al expresar más bien relaciones de complementariedad que de exclusión.

El concepto, en primer lugar, ostenta una doble naturaleza: el honor se fundamenta a la vez en una conducta ejemplar y en un status social. Aunque estos dos aspectos coexisten para cada sexo, se puede ilustrar mejor el primero con la «vergüenza» femenina y el segundo con la precedencia masculina. Esta doble naturaleza del concepto de honor no supone conflictos para los hombres: la precedencia, el rango, prevalecerán siempre sobre la necesidad de virtud personal. En cambio, para las mujeres el conflicto existe, pues el honor-virtud toma una importancia particular en el campo sexual y la preservación de la pureza. En la sociedad andaluza descrita por Pitt-Rivers, las familias de clase más altas se preocupan bastante poco por el honor sexual de las mujeres, dado su rango social. Pero ¿acaso se puede seguir defendiendo - en el caso femenino- que el criterio de honor de clase siempre ha prevalecido sobre el del honor debido al sexo?

En segundo lugar, según Guichard ${ }^{2}$ : «el honor, en sus relaciones con la condición femenina, debía, pues, concebirse de manera muy diferente por los occidentales y los orientales». El origen de dicha diversidad radicaría en las formas de organización social, al estar estructurados los primeros en una sociedad patriarcal exógama, los segundos en grupos patrilineales endógamos. En el sistema occidental, la riqueza parece constituir un determinante del honor. Esto implicaría la existencia de un papel importante de la alianza y del parentesco en línea matrilineal que justificaría la circulación de las mujeres, ya que éstas pueden aportar nobleza, riqueza y honor. En el código oriental, los componentes del honor parecen no variar con la clase social. Ya que «el honor tiene sus límites geográficos con el espacio "sagrado"... del hogar» ${ }^{3}$, entonces la endogamia es parte de esta estructura.

Por fin, la coexistencia de dos sustantivos, el honor y la honra, sugiere a la vez la complejidad de dicho valor y la importancia particular que adquiere

' Julian Pitr-Rivers, Anthropologie de l'bonneur, París, Le Sycomore, 1983. Este párrafo se basa también en los trabajos de Julio Caro BARoJA, Honour and shame, editado por J. G. Peristiany, Londres, The Trinity Press, 1965; Pierre Guich Ard, Structures sociales «orientales» et «occidentales» dans l'Espagne musulmane, París, Mouton, 1977, y Claude Chauchads, Honneur, morale et société dans l'Espagne de Philippe II, París, Editions du CNRS, 1984.

${ }^{2}$ P. GuIC H ARD, op. cit., p. 96.

${ }^{3}$ Ibid., p. 93. 
en la dinámica de la sociedad española. Hoy día, única en los países europeos, la legislación española reconoce y sanciona los delitos contra el honor: la «Ley de Protección Civil del Derecho al Honor, a la Intimidad Personal y Familiar y a la Propia Imagen», aprobada en mayo de 1982, constituye incluso una ampliación del «Fuero.de los Españoles» de $1945^{4}$.

Como valor moral, el concepto del honor masculino ha sufrido una gran evolución, sobre todo en relación con el trabajo.

Hasta el siglo xvin, el honor, según el modelo de la élite, excluía el ejercicio de un trabajo remunerado: un aristócrata se rebajaba al ejercer una profesión. El empobrecimiento de la aristocracia hace aparecer situaciones conflictivas, y el hidalgo arruinado, pero que se niega a trabajar para salvar su honor, se vuelve figura literaria (Lazarillo de Tormes). En cambio, el trabajo corresponde a las clases medias e inferiores de la sociedad, que carecen, por definición, de honor. Es la regla de la clase ociosa ${ }^{5}$.

Paralelamente a la especialización de lo económico en la sociedad y al surgimiento en la escena social de una clase mercantil dotada de medios materiales, el ejercicio de un trabajo se vuelve más compatible con el concepto del honor. Parece que en los orígenes del capitalismo, entre los calvinistas, empezaron a prevalecer el honor-virtud, el sentido del ahorro, la posesión material como meta bajo la forma de acumulación, en detrimento del honor-precedencia, del prestigio conquistado por el intermedio de la beneficencia y la redistribución. Al honor del rentista le sustituye el honor del trabajador, siempre que éste se haya enriquecido ${ }^{6}$. Dicha evolución la estigmatiza Veblen ${ }^{7}$ : «uno se honraba al abstenerse de todo trabajo: hoy día, la decencia lo exige».

En cuanto al concepto del trabajo, el honor femenino — sigo refiriéndome a la clase del ocio- parece seguir la misma evolución que el honor masculino. Como lo nota Veblen ${ }^{8}$ : «en aquellos felices días del régimen patriarcal, la esposa pasaba su tiempo sin hacer nada y manifestándolo; en cambio, en la fase de pacifismo avanzado, se afana diligentemente en las tareas del hogar». Ahora bien, en esto termina cualquier similitud con el honor masculino, ya que el sistema del honor corresponde a la distribución de los papeles en la familia nuclear. Especialmente, como lo nota Pitt-Rivers ${ }^{9}$ : «una mujer la [la vergüenza] preserva al abstenerse de las acciones que son propias de los hombres, lo que es posible y necesario teniendo en cuenta la división del trabajo». Por esto, ya que «el honor masculino está orientado hacia el exterior

4 Fuero de los Españoles, 1945, artículo 4, y Código Penal, artículos 467-475.

s Thorstein Veblen, Théorie de la classe de loisir, París, Gallimard, 1970. (Edición española: Teoria de la clase ociosa, Hyspamérica Ed., 1985.)

' Max Weber, L'éthique protestante et l'esprit du capitalisme, París, Plon, 1964. (Edición española: La ética protestante y el espiritu del capitalismo, Orbis Ed., 1985.)

7 T. VEBLEN, op. cit., p. 30.

${ }^{8}$ Ibid., p. 65.

9 J. Pitt-Rivers, op. cit., p. 79. 
y el honor femenino hacia el interior» ${ }^{10}$, sólo el trabajo interior forma parte del sistema del honor femenino.

Sin embargo, el trabajo exterior de los varones y el trabajo interior de las mujeres no resultan simétricos, pues las tareas domésticas están integradas en categorías morales que comprehenden desde el deber hasta el placer impuesto, pero que quedan alejadas en todos los casos del campo de la economía. Parece que uno de los elementos del honor femenino consiste precisamente en borrarle a la actividad doméstica todas las características de un trabajo - status y remuneración-, tal vez por no invadir en ninguna forma el territorio de los hombres y porque siguen pesando sobre la actividad femenina todas las obligaciones de un modo de producción familiar y patriarcal.

A este respecto, queda significativa la designación de la actividad doméstica que incumbe a la mujer con los términos «sus labores» o «labores propias de su sexo». En esto se encuentra, por un lado, cierta carga emocional: «labor» sugiere, a diferencia del concepto de trabajo, un contenido moral, que puede remitir a la idea de vocación o deber. Por otra parte, el término parece muy relacionado con la esfera femenina ${ }^{11}$ : además de designar todos los trabajos en el campo de la costura y del tejido, y de pasar a caracterizar, sin duda por extensión, toda clase de actividad doméstica femenina, se emplea también para calificar la escuela, y exclusivamente para las niñas. Por otro lado, despide cierta impresión de arcaísmo: en los casos en que «labor» no designa una actividad típicamente femenina, se aplica a los trabajos agrícolas. Parece, por lo tanto, participar del concepto de una economía de subsistencia y de un modo de producción doméstico, en los cuales reinaba la división tradicional del trabajo entre los sexos.

La imagen de la mujer productiva forma parte de estos deberes morales -recuperados por la ideología cristiana ${ }^{12}$ - que contribuyen al honor de la esposa, modelo de la mujer laica. Pero, contenido en el mismo término de «labores», está definido de forma restrictiva su campo de actividad. Se le exige a la mujer una doble producción: sea cual sea su categoría social, una mujer ha de producir hijos, percibidos como herederos en las clases más acomodadas y como mano de obra en las clases desfavorecidas. Por supuesto, la producción doméstica no la realizan directamente las mujeres en cuanto nos situamos en un nivel social más elevado. Pero su organización y su entera responsabilidad les incumben. En cambio, el honor femenino queda incompatible con el ejercicio de un trabajo profesional. Esta actitud subsiste hasta ahora, en particular en Andalucía, ya que Pitt-Rivers nota para las viudas que se lanzan a los negocios: «se han vuelto en cierta forma machos por subrogación» ${ }^{13}$.

Es posible preguntarse si el concepto del trabajo en este código del honor

10 Ibid., p. 128.

" María Moliner, Diccionario de uso del español, Madrid, Gredos, 1984.

12 Fray Luis de LEón, La perfecta casada, Madrid, Ediciones Aguilar, 1944.

${ }^{13}$ PitT-Rrvers, op. cit., p. 131. 
corresponde al que se encuentra en el sistema de valores machistas, vigente principalmente en las culturas hispánicas contemporáneas.

Varios autores ${ }^{14}$ subrayan las diferencias: «si el machismo puede evocar a veces la antigua moral del honor es únicamente como forma degradada de ésta». Describen el machismo sólo como cultura popular y en medios desfavorecidos. En lo que se refiere a la problemática del trabajo, para el varón, el ejercicio de una actividad remunerada no parece forzosamente positivo, sino, más bien, la aptitud para mantener financieramente a su familia. El número de hijos constituye la prueba de la potencia sexual, pero también económica. No importa tanto de dónde procede el dinero, y las actividades ilegales también participan en demostrar que el hombre es un macho.

En condiciones económicas precarias, el trabajo mercantil de la mujer se vuelve imprescindible para la supervivencia del hogar. Aunque este poder económico femenino preocupa e introduce confusión en los papeles tradicionales, es inevitable. Además, al definir el machismo como «una poligamia sin verdadera territorialidad ni total paternidad», Bejin y García Guadilla ${ }^{15}$ muestran la importancia de la estabilidad del hogar materno frente a la itinerancia del hombre, que oscila entre varias familias más o menos legítimas. Parece, entonces, que sólo la extrema valorización de los hijos es lo que permite no conferir valor negativo al trabajo femenino remunerado, en la medida en que éste interviene cuando se carece del apoyo masculino.

En el siglo $\mathrm{xx}$, las reglas del honor tienden a difuminarse. Sin embargo, a través tanto de la ideología política como de la moral cristiana, el discurso social sigue oponiéndose al trabajo mercantil femenino.

\section{La expresión de recbazo del trabajo mercantil femenino}

Las distintas corrientes de ideas que se discuten en la España de la primera mitad de este siglo, por diversas y opuestas que sean, evocan de forma casi uniforme el trabajo mercantil femenino. Bajo posiciones oficiales, la problemática del trabajo de las mujeres suscita, sin embargo, en la mayoría de los casos una polémica.

Dos actitudes parecen prevalecer a este respecto: una concepción destinada a las clases trabajadoras, en las cuales el problema de la incorporación de la mujer a la fuerza de trabajo se plantea en términos reales, y está vivido negativamente en términos de competencia. Una segunda concepción procedente

14 André Bejin y Naty García Guadilla, «Sept thèses erronées sur le machisme latino-américain", Cabiers Internationaux de Sociologie, vol. LXXVI, 1984, pp. 21-28, p. 24; David D. GILMORE y Margaret M. GILMORE, «Sobre los machos y los matriarcados: el mito machista en Andalucía», Etbnica, vol. 14, 1978, pp. 147-159; Claudia FONSECA, «Valeur marchande, amour maternel et survie», Annales, año 40, núm. 5 , 1985, pp. 991-1022.

${ }^{15}$ A. Bejin y N. García Guadilla, op. cit., p. 24. 
de las clases acomodadas, en las cuales el trabajo mercantil femenino no reviste la misma necesidad económica. Lo considera más como una amenaza para el equilibrio tradicional de la familia, e insiste entonces en términos positivos sobre el papel específico de las mujeres en la sociedad.

Conviene notar que las organizaciones femeninas se encuentran también separadas por esta división de clase. Los grupos de mujeres anarquistas y marxistas luchan, en el interior o más o menos al margen de los partidos, para defender el derecho al empleo femenino, en contradicción y/o enfrentamiento con la doctrina política oficial. Los grupos organizados de mujeres de la segunda concepción se encuentran, en cambio, en perfecta armonía con los partidos oficiales y hasta destacan en primera línea.

En conjunto, pocos ideólogos de la última mitad del siglo xIX o del principio del siglo $\mathrm{xx}$ ostentan posiciones favorables al trabajo mercantil femenino. Se nota una oposición franca por parte de Proudhon; Marx ${ }^{16}$ parece considerar el trabajo doméstico como condición natural de la mujer. Sólo Engels ${ }^{17}$ plantea el problema al afirmar la necesidad de colectivizar las actividades arrinconadas por el capitalismo en la esfera doméstica.

Sin lugar a duda, surgen, a finales del siglo XIX, en los congresos de los movimientos obreros anarquistas y socialistas resoluciones a favor del trabajo asalariado de las mujeres, de su incorporación a los órganos directivos de los sindicatos y de la igualdad de salarios: en el Congreso Obrero de la Federación Anarquista en Zaragoza, en 1879; también en el programa del Partido Socialista Obrero Español, a partir de $1888^{18}$. Sin embargo, al mismo tiempo que se denuncia la doble desvalorización del trabajo femenino en el sector mercantil y doméstico, la problemática está centrada en las consecuencias para el obrero, y traduce el miedo a la competencia que constituye la mano de obra femenina.

A nivel práctico, a pesar de las tomas de posición oficiales y la evidente contradicción con las teorías igualitarias que inspiran estos movimientos, la ideología patriarcal subsiste y las protestas en contra de la mano de obra femenina se expresan, sobre todo, a tres niveles: la pérdida de puestos de trabajo; la descualificación de los empleos, ocupados en mayoría por mujeres; su bajo nivel de concienciación y su insuficiente combatividad política. Por lo tanto, las resoluciones de los congresos desembocan solamente en medidas de protección específica del trabajo femenino: el Pleno Nacional de las Secciones Regionales de la Confederación Nacional del Trabajo, en 1938, no concibe que la obrera pueda ocupar todos los puestos de trabajo en la producción, por

${ }^{16}$ Karl Marx, Le capital, París, Gallimard, 1963, p. 940. (Edición española: El capital, Orbis Ed., 1986.)

${ }_{17}$ Friedrich ENGELS, L'origine de la famille, de la propriété privée et de l'Etat, París, Editions Sociales, 1975. (Edición española: Origen de la familia, la propiedad privada y el Estado, Ed. Planeta, 1986.)

${ }_{18}$ Mary NAS H, Mujer y movimiento obrero en España, 1931-1939, Barcelona, Editorial Fontana, 1981, pp. 63 y 146. 
miedo a que ciertas actividades «inadecuadas biológicamente a su condición sexual y temperamental pudiesen originar una degeneración de la raza» ${ }^{19}$.

Del mismo modo, Margarita Nelken, en el seno del Partido Socialista Obrero Español, define claramente el predominio de la función fisiológica de reproducción de la mujer cuando escribe «antes que obrera, la mujer es esposa y madre» ${ }^{20}$. Propone, así, una serie de medidas limitativas del empleo femenino (sobre todo condiciones de horarios) para que la mujer pueda seguir asegurando la doble jornada de trabajo.

En lo que se refiere al Partido Comunista ortodoxo, parece que no distingue la problemática del trabajo femenino del planteamiento general fundamentado en la explotación de las masas obreras. De hecho, escasos individuos y pequeños grupos, en el seno de los partidos, se distancian frente a esas posturas oficiales. Así, pues, sólo Dolores Ibarruri, en el Partido Comunista, plantea el problema femenino en términos específicos y lamenta que sus camaradas del partido guarden arraigados «los conceptos árabe y católico de la inferioridad de la mujer» ${ }^{21}$.

En el seno de la Federación Anarquista, escasas mujeres, agrupadas en torno de la revista Mujeres Libres, en 1936, reivindican el derecho al trabajo mercantil, y consideran prioritarias la formación técnica y profesional femenina, y la creación de servicios de sustitución a las tareas domésticas. Los partidos marxistas disidentes, que llegarán a formar el Partido Obrero de Unificación Marxista en 1935, hacen también un análisis separado del trabajo mercantil femenino.

Este debate adquiere repentinamente mucha agudeza al estallar la guerra civil, al mismo tiempo que vuelve a manifestarse un interés coyuntural por la mano de obra femenina a causa de la apremiante necesidad de asegurar la producción en la retaguardia. La incorporación de las mujeres a la fuerza de trabajo viene a ser entonces un objetivo primordial y entra en el programa del Partido Comunista de España y del Partido Socialista Unificado de Cataluña, ya que la sustitución de los hombres en sus puestos de trabajo permite la constitución de un ejército masculino regular con el mantenimiento de los niveles de producción. Así, el modelo femenino presentado por la Asociación de Mujeres Antifascistas, que lucha por la movilización femenina frente a la guerra, es la mujer que, para que su compañero vaya a su puesto de combate, le sustituye en el trabajo.

En la realidad, la opinión general predomina en contra del trabajo mercantil femenino. Al ser percibida como competidora con el trabajo masculino, la incorporación de las mujeres casadas en el sector mercantil no puede tener

19 Citado por M. NASH, op. cit., p. 66.

${ }^{20}$ Margarita Nelken, La condición social de la mujer en España, Madrid, Ediciones CVS, 1975, p. 96.

${ }^{21}$ Dolores IbarruRI, iA las mujeres madrileñas!, Ediciones del Comité Provincial de Madrid del Partido Comunista, citado por M. NASH, op. cit., p. 178. 
más justificación que la economía: si el trabajo femenino constituye la única fuente de ingresos familiar, o si completa un salario masculino insuficiente.

Resulta difícil concluir en el debate de la competencia femenina. En un primer análisis, es evidente que la llegada de una nueva fuente de mano de obra introduce más competencia en el mercado de empleo. Se notará, sin embargo, que, precisamente a causa de las condiciones discriminatorias de empleo impuestas a las mujeres (descritas particularmente para los principios de este siglo por Capel Martínez) ${ }^{22}$ —que consisten a la vez en salarios inferiores y en una inserción diferenciada en las categorías profesionales-, la competencia es pocas veces real. La femenización de ciertas ramas de actividad parece corresponder más bien a la introducción de nuevas tecnologías que a un simple ahorro en los costes de trabajo en un sector tradicional: el decrecimiento del coste del trabajo permite, al modificar el equilibrio de los factores de producción (capital/trabajo), la mecanización. Esta situación queda perfectamente demostrada en el caso de la Compañía Telefónica ${ }^{23}$.

La puesta en evidencia del papel específico de las mujeres está presente en la casi totalidad de los movimientos políticos. Sin embargo, adquiere un relieve particular cuando el trabajo mercantil femenino no es totalmente imprescindible para la supervivencia económica del hogar. Se presenta entonces la actividad profesional de las amas de casa como un peligro moral para el equilibrio de la familia y se acentúa la «misión» particular de la mujer en la sociedad.

En la primera mitad del siglo $\mathrm{xx}$, esta concepción está expresada sobre todo por la Iglesia y en el seno del partido nacional sindicalista de la Falange.

La prensa femenina ${ }^{24}$ católica sigue apoyándose en el ideal de Fray Luis de León ${ }^{25}$ para promover el arquetipo de la mujer cristiana: se trata de la madre, alma del hogar, dedicada por completo a sus hijos y a su marido. En sus momentos de ocio ayuda a los pobres. La problemática del trabajo mercantil femenino ni se considera, ya que queda claro que sólo la necesidad económica puede llevar a tales extremos. En tal caso, se prefiere la suerte de la empleada de casa a la de la obrera, al considerar el servicio doméstico como una oportunidad ejemplar de aprender a ser una buena ama de casa y madre de familia. Numerosas asociaciones y revistas difunden estas opiniones.

La ideología del Partido Falange Española, arraigada en el catolicismo, defiende la concepción de una vida de sumisión, de servicio, de ofrenda y de abnegación de las mujeres, para quienes el matrimonio debe constituir la meta

22 Rosa María Capel Martínez, El trabajo y la educación de la mujer en España (1900-1930), Madrid, Ministerio de Cultura, 1982.

${ }^{23}$ Cristina Borderías Mondéjar, Evolución de la división sexual del trabajo. Barcelona 1924-1980, Barcelona, Universidad Autónoma, 1984.

${ }^{24}$ Informaciones sobre la prensa femenina se encuentran particularmente en Adolfo Perinat y M." Isabel Marrades, Mujer, prensa y sociedad en España, 1800-1939, Madrid, Centro de Investigaciones Sociológicas, 1980.

${ }^{25}$ Fray LUIS DE LEÓN, op. cit. 
prioritaria y excluir toda actividad profesional. José Antonio Primo de Rivera declaraba en 1935: «Tampoco somos feministas. No entendemos que la manera de respetar a la mujer consista en sustraerla a su magnífico destino y entregarla a funciones varoniles...» ${ }^{26}$. La Sección Femenina, lejos de provocar una polémica acerca de estas posiciones, las asume plenamente bajo la dirección de la propia hermana de José Antonio, Pilar Primo de Rivera.

El régimen franquista reafirma por su cuenta la distinción trabajo masculino/servicio femenino del movimiento falangista. Se encuentra así una solución durante la guerra para recurrir a la mano de obra femenina sin otorgarle un estatuto en la fuerza de trabajo. Creado por Decreto el 7 de octubre de 1937, el Servicio Social se destina a desarrollar la vocación femenina de abnegación. De hecho, se trata de una movilización forzosa de las mujeres entre los 17 y 35 años, durante un período mínimo de seis meses, y que puede llevar consigo su transferencia fuera de su lugar de residencia. Esta mano de obra femenina es utilizada en las instituciones militares, los hospitales, los lavaderos del frente, los talleres. El Decreto del 31 de mayo de 1940 adapta el Servicio Social a los tiempos de paz, al darle una nueva función educativa, la de preparar a la mujer a su futuro papel de madre de familia. El instrumento de movilización de la mano de obra femenina se usa entonces con fines de propaganda, para mejorar la productividad doméstica de las mujeres ${ }^{27}$.

En esta perspectiva, el definir una vocación natural para la mujer impide plantear la problemática del trabajo mercantil femenino.

La práctica matiza, por supuesto, estas posiciones, y cierto consenso se establece acerca del trabajo femenino, para disimularlo en las clases acomodadas y lamentarlo en las clases desfavorecidas.

A través de la prensa femenina de modas y de salones, se pueden apreciar los modelos sociales. Así, la élite guarda la concepción del trabajo como actividad de ocio. Estas mujeres se ven, sobre todo, como esposas modelos y madres abnegadas, que dedican una parte de su tiempo al enriquecimiento del espíritu y a las obras de beneficencia. Las clases medias reservan el trabajo remunerado a las mujeres solteras. El trabajo fuera del hogar parece inconciliable con los deberes matrimoniales, maternos y domésticos. Sin embargo, el empobrecimiento de dichas clases reactiva la polémica. Un verdadero conflicto moral se plantea entre la reconquista del bienestar material, y, por lo tanto, del status social gracias al trabajo, y la incompatibilidad con la dignidad de la mujer burguesa. Este conflicto favorece la aceptación y el desarrollo del trabajo a domicilio, que, aunque infrapagado en relación con el mismo trabajo en talleres, permite salvar las apariencias necesarias a la preservación del honor

26 Arriba, núm. 7, 2 mayo 1935, citado por María Teresa Gallego Méndez, Mujer, Falange y Franquismo, Madrid, Ediciones Taurus, 1983, p. 34.

${ }^{27} \mathrm{M}^{\text {a }}$ T. Gallego MÉNDEZ, op. cit. 
femenino, así como obedecer a las normas de su categoría social ${ }^{28}$. En cuanto a las mujeres de las clases desfavorecidas, no se puede esconder su incorporación a la fuerza de trabajo desde mediados del siglo xix. La prensa de modas y salones alude raras veces a esta realidad y evoca para la mujer burguesa sólo a aquellas trabajadoras con las cuales puede estar en contacto directo: nodrizas, niñeras, empleadas domésticas, planchadoras, bordadoras... Aun en Cataluña, región especialmente concernida por el trabajo mercantil femenino suscitado por el desarrollo de la industrialización, la prensa femenina habla poco del trabajo asalariado. Al fin y al cabo, sólo la prensa católica se atreve a describir la suerte de las obreras, a las que conviene educar y proteger contra las ideas revolucionarias ${ }^{29}$.

Hoy día, el discurso político oficial se ha visto obligado a corregir esta concepción restrictiva del trabajo femenino. Sin embargo, se nota la persistencia del término «sus labores» para designar, en todos los documentos oficiales, la actividad de las amas de casa. Las normas sociales y su interiorización siguen cargando con el peso de los valores tradicionales y se oponen todavía al trabajo mercantil de las mujeres.

Del lado masculino, una encuesta de la Fundación FIES, realizada en $1979^{30}$, revela que el 59 por 100 de los 2.114 cabezas de familia entrevistados se muestran hostiles al empleo de las mujeres casadas: 32 por 100 piensan que habría que impedirlo; 27 por 100, dificultarlo.

Del lado femenino, un estudio del Instituto de la Mujer, fundamentado sobre discusiones de grupos de mujeres ${ }^{31}$, revela que el conflicto trabajo exterior/trabajo interior sigue planteándose, sean cuales sean el status de actividad, el nivel de educación, la experiencia profesional, en cuanto aparece la maternidad.

\section{Economía del bonor femenino}

La salvaguardia del honor femenino dependía, pues, del respeto a la división tradicional del trabajo: tener por meta el matrimonio y la procreación, desempeñar las tareas domésticas, quedarse apartada de la esfera pública. Ahora bien, las tasas demográficas, en diferentes etapas, ostentan una disminución tendencial al considerar el conjunto del siglo xx; la producción doméstica la ha absorbido en parte la esfera mercantil; el crecimiento de las tasas de esco-

${ }^{28}$ Geraldine M. Scanlon, La polémica teminista en la España contemporánea (18681974), Madrid, Ediciones Siglo XXI de España, 1976.

${ }^{29}$ Acción Femenina Católica, núm. 4, 1912, citado por A. Perinat y M." I. MarraDES, op. cit., p. 248.

${ }^{30}$ Fundación FIES, «Actitudes de la población española ante el empleo y el paro», Papeles de Economía Española, núm. 8, 1981, pp. 322-344.

${ }^{31}$ María Angeles Sallé y José Ignacio CaSAs, Efectos de la crisis económica sobre el trabajo de las mujeres, Instituto de la Mujer, 1986. 
larización y de participación laboral demuestra que cada vez más mujeres salen del ámbito cerrado del hogar.

La evolución de las tasas de natalidad españolas ${ }^{32}$ se caracteriza por dos factores: a nivel global, se observa el mismo decrecimiento que en los demás países occidentales desde el principio de este siglo, a pesar del boom natalista de los años sesenta. Sin embargo, cabe notar que las tasas españolas guardan un nivel más bien medio en comparación con los países de la OCDE en 1950, mientras se muestran elevados al principio de los años setenta. El número medio de hijos por mujer aumenta entre 1950 y 1970.

Esta disminución tendencial de la natalidad se puede explicar por la incompatibilidad entre los papeles femeninos de productora en el mercado de trabajo y productora de bienes y servicios en el hogar. En los países industrializados se revelan, en general, correlaciones negativas entre tasa de fertilidad y participación en la fuerza de trabajo. El decrecimiento de las tasas de natalidad parece, entre otros factores, relacionado con la mejora del nivel de salario femenino a lo largo de este siglo ${ }^{33}$.

Los estudios del caso español son escasos ${ }^{34}$. Sobre todo, no se dispone de suficientes datos para preparar trabajos empíricos rigurosos y explicar, por ejemplo, las variaciones del número de hijos en los últimos cuarenta años.

La producción de bienes y servicios en el hogar se registra difícilmente a nivel cuantitativo. Para una evaluación en términos monetarios, los datos de las Encuestas de Presupuestos Familiares del Instituto Nacional de Estadística no especifican la proporción del autoconsumo de los hogares españoles. Para una evaluación en términos de tiempo no se cuenta con ninguna encuesta detallada de presupuestos de tiempo. Por lo tanto, sólo estimaciones básicas se han llevado a cabo hasta la fecha.

En una perspectiva longitudinal, sólo se puede conocer la proporción de población femenina que desempeña a tiempo completo las tareas domésticas, de acuerdo con el rol de esposa y madre que le asigna la ideología tradicional. Dichos cálculos han podido realizarse solamente con base en los Censos de 1950 y 1960, y luego con los datos de las Encuestas de Población Activa del Instituto Nacional de Estadística. Estas tasas de actividad doméstica a tiempo completo disminuyen progresivamente: en 1950, el trabajo en el hogar repre-

${ }^{32}$ La evolución demográfica está estudiada, por ejemplo, en Salustiano deL Campo, Análisis de la población española, Barcelona, Editorial Ariel, 1975; Isabel Agüero y Alberto Olano Rey, "La intensa caída reciente de la fecundidad y la nupcialidad en España», en Familia y cambio social en España, editado por Rosa Conde, Madrid, CIS, 1982; Pilar Alcobendas Tirado, Datos sobre el trabajo de la mujer en España, Madrid, CIS, 1983.

${ }^{33}$ James P. Smith y Michael P. WARD, «Time-series growth in the female labor force», Journal of Labor Economics, vol. 3, 1985, pp. 59-90.

${ }^{3}$ Carlos Pereira de Grado, Una aplicación de la nueva economía de la familia a la demanda de bijos, mimeo, Universidad Literaria de Valencia, 1973; Michelle Riboud, Une analyse économique de la fécondité, mimeo, Université d'Orléans, 1982, y Feliciano HeRnÁNDEZ IgLEsias y Michelle Riboud, Trends in labour force participation of spanish women, mimeo, Université d'Orléans, 1983. 
Actividad productiva de las mujeres, 1900-1986

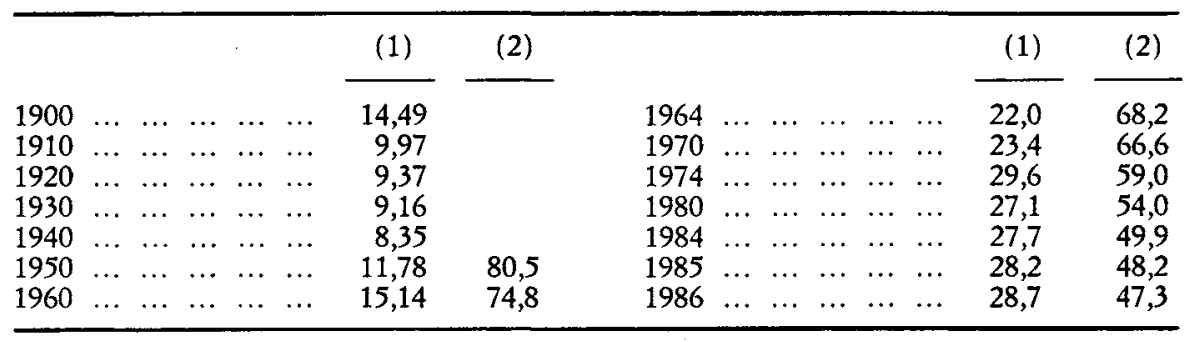

(1) Tasa de actividad mercantil.

(2) Tasa de actividad doméstica a tiempo completo.

Fuentes: Elaboración propia según datos de Censos de Población (hasta 1960) y Encuestas de Población Activa (4..$^{\circ}$ trimestre, a partir de 1964), Madrid, INE.

sentaba la especialización del 80,5 por 100 de las mujeres en edad de trabajar. En 1986 ocupaba todavía a tiempo completo cerca de la mitad de las mujeres. Por edad, entre 1964 y 1985 aparece la principal caída de esta tasa para las categorías más jóvenes, lo que confirma el alargamiento de la escolaridad, así como el aplazamiento del matrimonio.

Una estimación ${ }^{35}$ con base en una encuesta realizada en 1984 evalúa las amas de casa en 10,9 millones, y el número de horas de trabajo doméstico efectuado por aquéllas entre los 33,7 y los 35 mil millones. Al valorar dicho trabajo con el coste de una empleada doméstica externa, la producción doméstica representa entre 3,2 y 3,4 millones de millones de pesetas.

A nivel de la educación como de la producción mercantil, la participación de las mujeres aumenta, incluso la de las mujeres casadas.

La tasa de analfabetismo femenino se mantiene superior a la tasa masculina, así como el nivel promedio de educación de la población femenina es todavía inferior al de la población masculina. Sin embargo, las tasas de escolarización en el ciclo secundario son ahora más elevadas para las mujeres que para los hombres ${ }^{36}$.

Aunque aumenta desde los años sesenta, la tasa de participación femenina en el mercado de trabajo queda muy baja en comparación con las cifras europeas y accidentales en general ${ }^{37}$. En 1986, la tasa de actividad femenina global es de 28,7 por 100 , y el de las mujeres unidas de solamente 21,2 por $100^{38}$. Los únicos datos disponibles para 1987 (primer trimestre) dan, respectivamente, 29,2 y 21,5 por 100 .

${ }^{35}$ France Caillavet, «El trabajo gratuito de las mujeres: de la economía familiar a la economía nacional», en De puertas adentro, editado por $\mathrm{M}$. A. Durán (en prensa).

${ }^{36}$ P. Alcobendas Tirado, op. cit.

${ }^{37}$ L'intégration des femmes dans l'économie, París, OCDE, 1985, y Journal of Labor Economics, vol. 3, núm. 1, parte 2.a 1985.

${ }^{38}$ Encuesta de Población Activa, Madrid, Instituto Nacional de Estadística, 4. trimestre 1986. 
Sin duda, los comportamientos acerca del trabajo de las mujeres han evolucionado. Pero es difícil pensar que sólo preocupaciones de justicia e igualdad han podido influir sobre valores tan arraigados en el discurso social. Destaca también, como uno de los principales motores de la progresión del trabajo mercantil femenino, el contexto económico prevaleciente y, sobre todo, las necesidades de la demanda de trabajo.

\section{LAS MUJERES FRENTE AL TRABAJO MERCANTIL}

Los obstáculos de orden ideológico al trabajo mercantil femenino no son, pues, desdeñables. Otras presiones se encuentran en un mercado de trabajo caracterizado, al parecer, por un excedente en la oferta de mano de obra. En este contexto, la evolución de la oferta femenina de trabajo registra diferentes fases:

1900-1960: la oferta femenina decrece hasta los años 1940, luego aumenta de nuevo. Sólo en 1960 la tasa de participación femenina recupera el nivel alcanzado en 1900 .

1960-1974: corresponde a una fase de expansión de la oferta femenina. 1975-1986: con pocas variaciones, la tasa de participación de las mujeres se queda en un nivel inferior al de 1975 .

El retroceso de la fuerza de trabajo femenina, 1900-1960

El excedente de mano de obra parece desempeñar en poca medida el papel asignado por la teoría del dualismo ${ }^{39}$. Revolución abortada o despegue gracias a la neutralidad observada durante la Primera Guerra Mundial, la fuerza de trabajo española se queda estática y el sector agrícola no libera su exceso de mano de obra antes de los años $1950^{40}$. La demanda de trabajo parece limitada, con el solo desarrollo de unos islotes industriales en el País

39 W. Arthur LEWIS, «Economic development with unlimited supplies of labour», The Manchester School, mayo 1954, pp. 139-191.

${ }^{40}$ Jordi Nadal, El fracaso de la revolución industrial en España, 1814-1913, Barcelona, Editorial Ariel, 1975; Javier BraÑa, Mikel Buesa y José Molero, «Los orígenes y el desarrollo del capitalismo en España», Información Comercial Española, junio 1976, pp. 119-135; Santiago Roldán, J. L. García Delgado y Juan Muñoz, La formación de la sociedad capitalista en España, 1914-1920, Madrid, CECA, 1973; Nicolás SÁNC h EZAlbornoz, España bace un siglo, una economia dual, Madrid, Alianza Universidad, 1977; Juan MuÑoz García, Santiago Roldán López y Angel Serrano Martínez EsteLLEZ, "Minería y capital extranjero en la articulación del modelo de desarrollo subordinado y dependiente de la economía española en la segunda mitad del siglo xix y los primeros años del siglo $\mathrm{xx}$ ", Información Comercial Española, núm. 514, junio 1976, pp. 59-89, y J. BRAÑa et al., op. cit. 
Vasco y en Cataluña. El nivel de combatividad obrera de estos focos puede hacer olvidar su poca importancia numérica frente al conjunto de la mano de obra.

Esta economía se ubicaría en la fase preliminar al modelo de desarrollo dual descrito por Lewis ${ }^{41}$, en la medida en que el sector capitalista español, sea en la agricultura, sea en torno a los focos de industrialización minera del País Vasco y textil de Cataluña, conserva estructuras artesanales, para las cuales la oferta local de mano de obra queda suficiente. ¿Atonía de la demanda o atonía de la oferta? Aun con una productividad marginal inferior en el sector agrario, en comparación con el resto de la economía, y una situación de subempleo, el traspaso no ha tenido lugar.

A pesar de un crecimiento en valor absoluto y una disminución de las tasas de actividad, la fuerza de trabajo ostenta el mismo reparto por sectores durante los cuarenta primeros años del siglo, al evolucionar con lentitud las estructuras económicas. Sólo dos fenómenos dan alguna dinámica a la composición de esta fuerza de trabajo, pero contribuyen a disminuir todavía más la importancia visible de su excedente.

El primero está constituido por los flujos de emigración exterior, que son relativamente importantes hasta 1914 y que luego se agotan poco a poco hasta la guerra civil ${ }^{42}$.

El segundo es la casi desaparición de la actividad mercantil femenina entre 1900 y 1940, según los datos de los Censos: la tasa de participación, que ya era poco elevada en 1900 (14,5 por 100), a la vez que iba disminuyendo desde el último cuarto del siglo xIX, alcanza apenas el 8,35 por 100 en 1940. Esta extinción del trabajo de las mujeres está acompañada por una redistribución de la mano de obra femenina entre los distintos sectores de actividad: desde 1910, las activas agrícolas ya no predominan, y el sector de los servicios vuelve a ser el primer empleador femenino en 1920 , con el 40,4 por 100 de la fuerza de trabajo ${ }^{43}$. Sin embargo, hay que considerar estos datos con cuidado. Si el crecimiento del sector terciario se debe, en efecto, al desarrollo del servicio doméstico y del pequeño comercio, empleos típicamente femeninos, en cambio, parece difícil creer en esta salida en masa de las mujeres del sector agrario. Nos encontramos aquí delante del proceso clásico de no-contabilización de la actividad femenina, particularmente frecuente en la agricultura, en la cual se puede más fácilmente asimilar el trabajo de la explo-

41 W. A. LEWIS, op. cit.

42 S. del Campo, op. cit.; Alfonso García Barbancho, Las migraciones españolas en 1961-65, Madrid, Instituto de Desarrollo Económico, 1970; Jaime Martín Moreno, "Aspectos demográficos del fenómeno de la emigración exterior», en Estudios de Economia del Trabajo en España, Madrid, Ministerio de Trabajo y Seguridad Social, 1985, pp. 393-426.

${ }^{43}$ Alvaro Soto Carmona, «Cuantificación de la mano de obra femenina (1860-1930)», en La mujer en la bistoria de España, siglos XVI-XX, Madrid, Universidad Autónoma, 1983, pp. $279-298$. 
tación familiar con las tareas domésticas. Por otra parte, la división tradicional del trabajo entre los sexos en la agricultura asigna a las mujeres las actividades periféricas a la producción, fácilmente «olvidadas». En caso de sobrepoblación rural, son, en primer lugar, las mujeres y los hijos los que aparecen como un recurso en mano de obra fácilmente utilizable, sea para el empleo en las fábricas o sea para el trabajo a domicilio: aquí también el trabajo femenino no deja huellas ${ }^{44}$.

El Fuero del Trabajo de 1938, vigente hasta finales de los años 1950, pone el mercado de trabajo bajo el control del Estado, que fija los salarios en un nivel próximo al mínimo de subsistencia. La industria española aprovecha poco este proceso de acumulación forzada: Serrano y Malo de Molina hablan de «la atonía total de la demanda de trabajo» ${ }^{45}$. No se produce entonces movilidad de la mano de obra. Sin embargo, algunas transformaciones se inician, sensibles al nivel de la importancia respectiva de los distintos sectores de actividad. La diferencia entre el sector terciario y secundario aparece, para ventaja de este último. Sobre todo, la proporción alcanzada por el sector primario en términos de mano de obra ya no es predominante: todavía cerca del 50 por 100 en 1950 , no representa más que el 41,7 por 100 en 1960.

El sector agrario empieza a vaciarse y la fuerza de trabajo femenina reaparece en las estadísticas. Los cálculos de Naredo y Leguina ${ }^{46}$ demuestran la importante disminución del número de activos masculinos, parcialmente compensado por la incorporación creciente de las mujeres a la fuerza de trabajo agrícola. Esta «entrada en el trabajo» de las mujeres, que interviene probablemente en el marco de pequeñas explotaciones familiares cuyo jefe de familia ha emigrado, manifiesta el papel de relevo tomado por la población femenina, al asumir de repente la responsabilidad de la explotación y de la familia. Estas activas agrícolas se encuentran, entre 1941 y 1950 , a la vez en las categorías de edad más elevadas ( 45 años y más) y las más jóvenes (10 a 19 años). Reaparecen, pues, en primer lugar en las estadísticas las generaciones de abuelas y de adolescentes. En los diez años. siguientes, 1951-1960, surge también el trabajo mercantil de las mujeres en período de reproducción, mientras que se acelera la salida de hombres activos. Esta reaparición, puramente estadística, según parece, de las mujeres en el sector agrícola mercantil entre 1940 y 1960 detiene la caída de la tasa de actividad femenina, que con 15,1 por 100 alcanza el nivel registrado en 1900. Pero con la diferencia de que el 72 por 100 de las activas pertenecen a sectores no agrarios, y especialmente al sector de los servicios.

${ }^{44}$ R. M. a Capel Martínez, op. cit., y Alvaro EsPina, «La participación femenina en la actividad económica: el caso español», en Familia y cambio social, editado por Rosa Conde, Madrid, Centro de Investigaciones Sociológicas, 1982, pp. 283-349.

${ }^{45}$ Angel Serrano y José Luis Malo De Molina, Salarios y mercado de trabajo en España, Madrid, Ediciones Blume, 1979.

${ }_{46}$ José Manuel Naredo y Joaquín Leguina, «El sector agrario, fuente de mano de obras, Información Comercial Española, abril 1973, pp. 73-106. 
En fase de reconstrucción, la escasa participación de las mujeres en el sector mercantil demuestra la importancia de la producción en el hogar. Sin embargo, y de forma paralela, tienen que compensar la hemorragia de activos masculinos en la agricultura.

\section{La rigidez de la demanda de trabajo femenino, 1960-1974}

Hay que esperar a 1959 para asistir a unas modificaciones fundamentales en el mercado del trabajo. Este período se termina en 1974, último año de crecimiento en valor absoluto del número de activos y ocupados: la tasa oficial de desempleo alcanza casi el 3 por 100. De hecho, la tasa corregida de desempleo, al incluir el volumen de emigración hacia Europa, ostenta la degradación regular del equilibrio del mercado de trabajo. Desde 1965, esta tasa supera el 5 por 100 , y alcanza el 8 por 100 en $1974^{47}$. Se presencia, efectivamente, una salida en masa de los activos del mercado de trabajo, que alcanzaría dos millones entre 1961 y 1970, contra un millón durante la década precedente.

Sin embargo, este excedente está poco absorbido por la industria interior, en primer lugar, a causa de la rigidez en la sustituibilidad entre los factores de producción. El desarrollo industrial, financiado ampliamente por inversiones extranjeras, se cumple con la implantación de modelos tecnológicos importados de países en los cuales prevalece, en cambio, un déficit de mano de obra. Estas técnicas son poco intensivas en trabajo, y especialmente en trabajo poco cualificado. Así que, a pesar de una situación global de oferta excedentaria de trabajo, la industria se encuentra frente a una penuria de mano de obra cualificada, lo que frena la demanda. La tensión se registra a nivel de los salarios: por una parte, éstos se quedan bajos, desde entonces fijados por negociaciones colectivas en las cuales los sindicatos verticales apoyan la política gubernamental; por otra parte, se observa la flexibilización de la escala de los salarios, y la demanda industrial provoca unas alzas importantes de las remuneraciones para la mano de obra cualificada. Así, pues, los costes del trabajo parecen haber crecido más que la productividad en la industria.

Un segundo fenómeno no favorece el empleo de fuerza de trabajo en la industria, debido a las transformaciones de la demanda interior de bienes y servicios, así como a la estructura de las exportaciones. En ambos casos, la evolución lleva al ahorro del factor trabajo ${ }^{48}$.

47 Población, actividad y ocupación en España, Madrid, Ministerio de Economía, 1979; José Ignacio PÉREz INFANTE, «Rasgos estructurales del empleo y paro en la formación social española», Información Comercial Española, núm. 553, 1979, pp. 64-90; J. MuÑoz García, S. Roldán lópez y A. Serrano Martínez Estellez, op. cit.

${ }^{48}$ Oscar Fanjul, Crecimiento y generación de empleo, Madrid, Instituto Nacional de Industria, 1975; José Luis Malo DE Molina, El proceso de ajuste del mercado de trabajo español durante la crisis económica, Madrid, Banco de España, mimeo, 1984; Jesús 
La disponibilidad de mano de obra femenina es sensible, también, con la progresión de la tasa de participación femenina, que alcanza un nivel máximo de 34,5 por 100 en el período $1964-1974^{49}$. Hay que notar que el crecimiento rápido, observado entre el primer dato proporcionado por la Encuesta de Población Activa de 1964, 22 por 100, y el del Censo de 1960, 15,1 por 100, se debe, seguramente, en su mayor parte a un cambio en la metodología estadística y, sobre todo, a una infravaloración de la mano de obra femenina en el sector agrícola.

Por otra parte, el fenómeno de la emigración empieza a afectar a la fuerza de trabajo femenina: 1961-1970 es la primera década que registra saldos migratorios negativos en el sector agrícola. Esta población se queda dentro del país: de 1964 a 1975, los flujos de emigración femenina con destino a Europa no han representado nunca más del 20 por 100 del total, y, además, disminuyen fuertemente a partir de $1968^{50}$.

Dentro de este periodo de progresión de la participación femenina, se pueden distinguir dos etapas: una primera fase, entre 1965 y 1970 , durante la cual la tasa de participación queda estancada cerca del 23 por 100; una segunda fase, entre 1970 y 1974 , durante la cual se asiste a un verdadero crecimiento del trabajo mercantil femenino. En el curso de cuatro años, la tasa de participación pasa de 26,5 por 100 a cerca de 30 por 100 . En el contexto general descrito anteriormente, la tasa de ocupación femenina refleja bien el estancamiento de la demanda de trabajo hasta $1970(+3,1$ por 100 desde 1964) y su súbita aceleración hasta $1974(+13,7$ por 100 , o sea, $+3,3$ por 100 de crecimiento anual).

El desfase de esta participación femenina en relación con el ciclo de expansión de la economía procede, según Espina y De Miguel ${ }^{51}$, del atraso relativo en el desarrollo del sector de los servicios no tradicionales. Por otra parte, las variaciones de la demanda tienen un impacto particular sobre las mujeres, ya que el componente coyuntural en la evolución de las tasas de participación afecta más a las tasas femeninas que masculinas. La flexibilidad de la oferta de trabajo de las mujeres frente a la coyuntura del empleo desempeña, entonces, un papel importante en la amortiguación del ciclo del desempleo. El carácter de ejército de reserva de la mano de obra femenina se aprecia también al observar el deterioro de la tasa de dependencia de la población, o sẹa, el número de personas a su cargo por activo ocupado, a partir de 1970. Preci-

Albarracín, «Empleo, productividad y actividad económica», Información Comercial Española, núm. 553,1979 , pp. 36-42.

${ }_{49}$ A continuación, las tasas de participación para el período 1964-1978 proceden de Población, actividad y ocupación en España, op. cit., y de Encuesta de Población Activa, Madrid, Instituto Nacional de Estadística, 4. ${ }^{\circ}$ trimestre 1979 a 1986.

${ }_{50}$ J. Martín Moreno, op. cit., y J. M. Naredo y J. Leguina, op. cit.

s1 Alvaro EsPina y Carmen DE Miguel, «Evolución y perspectivas de las tasas de actividad en España, con especial referencia a la tasa de actividad femenina», en Seminario franco-español sobre problemas actuales de la economia del empleo, Madrid, Ministerio de Economía, 1978, pp. 63-95. 
samente tiene lugar en esta fecha la incorporación a la fuerza de trabajo de las categorías de mujeres cuya oferta es particularmente rígida (mujeres en período de reproducción), y la tasa de dependencia vuelve entonces a los valores medios de los años anteriores ${ }^{52}$. Se revela allí el hecho novedoso de la aparición en el mercado de las mujeres con niños a su cargo.

El análisis por categorías de edad permite aclarar el comportamiento de la oferta: durante el período 1964-1970 se nota la entrada de las de 2024 años en el mercado de trabajo, al ritmo de 5,9 por 100 al año. Sin duda, hay que destacar la influencia del aumento del nivel de educación femenina en una categoría de edad en la cual predominan las solteras. En el período 1970-1974 se percibe el despegue de la participación femenina para todas las edades entre 25 y 64 años. Todas las tasas de crecimiento anuales superan el 4 por 100 al año, y hasta alcanzan el 9,6 por 100 para los 30-34 años y el 8 por 100 para los 35-39 y $45-49$ años. Se trata de la incorporación de las mujeres casadas y en edad de reproducción en el mercado de trabajo. Sáez Buesa ${ }^{53}$ describe las etapas de la vida activa de las mujeres en los años sesenta a setenta. El período de actividad mercantil se separa en dos: en primer lugar, las edades promedios al entrar en el mercado de trabajo no coinciden, a diferencia de los hombres, con la edad de salida del sistema educativo; luego, después del primer período de actividad, la edad de salida se acerca a los 26 años, con una experiencia promedio de diez años; la edad media de vuelta al mercado de trabajo se sitúa entre los 43 y los 46 años, con la salida definitiva cerca de los 66 años. La duración de este segundo período de actividad mercantil varía bastante. En total, el período de retirada del mercado de trabajo dura entre 17 y 20 años. La ruptura de este fenómeno de discontinuidad constituye, sin lugar a duda, el rasgo más sobresaliente de la fase 1970-1974.

\section{La presión de la oferta femenina de trabajo, 1974-1986}

En fase de expansión, la economía ya no generaba suficiente empleo para la población en edad de trabajar. Al desempleo de la prosperidad sigue el desempleo de la crisis. Los efectos de la crisis petrolera se revelan, desde 1973, sobre las tasas de desempleo, que de repente aumentan. Las tasas de participación se ven afectadas a partir de 1975 . El brusco agotamiento de los flujos de emigración y el nuevo comportamiento de la oferta femenina de trabajo empeoran un problema estructural. La emigración con destino a Europa sufre las repercusiones de la crisis en esos países y alcanza su nivel más bajo en $1977^{54}$.

52 Julio AlCAIdE INCH AUSTI, «La población española y el trabajo», Papeles de Economía Española, núm. 8, 1981, pp. 32-39.

${ }^{53}$ Armando SÁEz Buesa, Pablación y actividad económica en España, Madrid, Siglo XXI Editores, 1975.

${ }_{54}$ J. Martín Moreno, op. cit. 
Las tasas de participación femenina quedan estancadas, con una tendencia a la baja. Se registra una variación de un $-0,4$ por 100 al año durante el período 1974-1986. Las de 25.39 años siguen, sin embargo, su progresión en el mercado del trabajo, mientras que las edades más jóvenes, así como las avanzadas, se retiran. Desde 1974, la tasa de ocupación de la mano de obra femenina va disminuyendo: en 1986 resulta inferior al nivel de 1964 . La tasa de desempleo culmina en 1986: 26 por 100 (19 por 100 para la mano de obra masculina), y parece seguir creciendo en 1987 (primer trimestre, últimos datos disponibles): 26,7 y 19,2 por 100 , respectivamente, lo que demuestra cierta resistencia de parte de la oferta femenina de trabajo por no volver a su papel clásico de ejército de reserva. Hay que notar que la combinación de las variables de sexo y edad hace observar tasas impresionantes. En 1986, la tasa de desempleo de las mujeres entre los 16 y los 19 años alcanza 57,1 por 100, y entre los 20 y los 24 años, 47,6 por 100. En el primer trimestre de 1987 alcanza, respectivamente, 55,5 y 48,3 por 100 .

Es posible, además, que estas cifras, ya de por sí muy altas en relación con el promedio europeo, se incrementen bajo el efecto de la expansión de la oferta de trabajo, y esto sin que tengamos en cuenta la coyuntura y sus efectos sobre la demanda. En efecto, irán llegando al mercado de trabajo generaciones demográficamente importantes, anteriores a la tendencia a la baja de la fecundidad, que comenzó en España relativamente tarde y se fue acelerando sólo a partir de $1974^{55}$.

En tales circunstancias de crisis es cuando despega la oferta femenina de trabajo.

Bajo las presiones conjuntas de la oferta de trabajo y del crecimiento de los costes de los factores se acentúa la segmentación del mercado de trabajo. Varios estudios ${ }^{56}$ constatan, efectivamente, la apertura del abanico salarial entre 1964 y 1976, lo que puede revelar la existencia de mercados internos de trabajo en un medio rígido en cuanto a condiciones salariales.

Esta segmentación se desarrolla en particular con la constitución de un sector subterráneo en la economía, como respuesta explícita a las imperfecciones del mercado de trabajo formal, concretamente la rigidez de los niveles salariales, siempre mayor hacia la baja que hacia el alza.

'Con una formulación tripartita del sector productivo, el triángulo de Gershuny ${ }^{57}$ demuestra cómo se nutre la economía subterránea: por un lado, la transferencia de actividades del sector mercantil formal se verifica cuando impera en éste una situación de paro, o también un precio real decreciente o

ss I. Agüero y A. Olano Rey, op. cit.

56 José Luis MALO DE Molina, «La estructura salarial española por ramas de actividad durante el período 1963-1975», y Felipe SÁEZ FERNÁNDEZ, «Salarios y segmentación del mercado de trabajo en España», en El mercado de trabajo en España, Madrid, Ministerio de Economía, 1982, pp. $57-96$ y pp. 97-116, y J. A. Martínez Serrano et al., op. cit.

${ }_{57}$ J. Gershuny, «The informal economy», Futures, febrero 1979, pp. 3-15. 
bien altos costos de producción; por otro lado, una parte de la producción doméstica puede ingresar en la economía subterránea, especialmente si la existencia de una fuerte tasa de paro estimula el crecimiento del empleo doméstico barato y sin declarar, condiciones totalmente compatibles con las características de la economía española.

Asimismo, el caso español podría validar la hipótesis de que el sector informal resulta de desequilibrios simultáneos ${ }^{58}$. Se debería a la conjunción de una situación de demanda excedentaria, a la vez, en el mercado de trabajo y en el de los bienes y servicios. Ahora bien, parece que el mercado de trabajo español se ha mostrado más sensible al déficit de mano de obra cualificada que al excedente de oferta de trabajo no cualificado. Por eso, no obstante el mantenimiento de una tasa de salario mínimo en un muy bajo nivel, se registraban tensiones hacia el alza de los salarios.

La economía subterránea repercute directamente en la mano de obra femenina ${ }^{59}$. Hoy día, el mercado de trabajo femenino resulta fuertemente segmentado entre, por una parte, una demanda de mano de obra muy cualificada, en la cual las mujeres se ven obligadas más que los hombres a dar pruebas de su capacidad, y, por otra parte, una demanda de mano de obra poco cualificada, que va sufriendo las incertidumbres del sector informal.

En efecto, se observa un doble fenómeno a partir de las tasas de actividad femenina por niveles de educación. Desde 1975 decrece la participación en la fuerza de trabajo de las mujeres con un nivel de estudios primarios o inferior, mientras que aumenta la de las mujeres con estudios secundarios o superiores. Por lo tanto, se van acentuando las diferencias entre 1975 y 1986, con más relevancia entre 1975 y 1980.

En definitiva, la evolución de las tasas de ocupación muestra que la demanda de empleo femenino se mantiene con una estabilidad curiosa durante el período 1964-1986: la brevedad de la fase de expansión de aquella demanda (entre 1971 y 1974) lleva a interrogarse sobre un eventual efecto de la coyuntura, ya que la tasa de ocupación de 1986 se revela cercana a la de 1964 . Es posible que el reparto de la fuerza de trabajo femenina por sectores se haya modificado de forma significativa durante ese periodo, pero, más que nada, ha reflejado de manera más aguda un movimiento que afectaba a la mano de obra en su globalidad.

El aumento de las tasas de paro revela la persistente rigidez de la demanda del sistema productivo frente a una oferta femenina creciente.

58 Edith Archambault y Xavier GrefFe, Les économies non officielles, Paris, Editions La Découverte, 1984, y Edmond Malinvaud, Essais sur la théorie du chômage, París, Calmann-Levy, 1983.

${ }^{59}$ Enric SANCH IS, El trabajo a domicilio en el Pais Valenciano, Madrid, Instituto de la Mujer, 1984, y Mujer y economía sumergida, Madrid, Comisiones Obreras, 1986. 


\section{CONCLUSION}

La incorporación de las mujeres españolas a la fuerza de trabajo se encuentra con muchos obstáculos: actuaban con pertinencia, primero, el concepto del honor femenino; luego, la vocación asignada a la mujer para, de un lado, proteger la economía de un flujo suplementario de mano de obra no cualificada dentro de un contexto de por sí excedentario y, de otro lado, para producir bienes y servicios a bajo costo dentro de una economía de casi subsistencia y, después, de reconstrucción.

Sin embargo, esta mano de obra se ha utilizado en forma muy oportuna a lo largo de todo este siglo, como lo demuestran varios niveles de análisis del trabajo femenino.

Primero, a nivel de las reacciones que provoca: el marcado recelo de los sindicatos masculinos frente a la competencia y la denuncia de las condiciones de explotación que sirven de marco al empleo femenino (trabajo a domicilio, en particular). Luego, en la recuperación que permite: movilización en la producción y recurso al trabajo benéfico durante la guerra civil. Por fin, en el papel clave que desempeña en el proceso de desarrollo de la economía española de la postguerra: supervivencia de las empresas agrícolas durante las hemorragias de activos masculinos; apoyo en la fase de expansión de la industria entre 1971 y 1974, gracias a la adaptación de la oferta de trabajo de las mujeres en edad de procrear, $y$, por último, incorporación en el sector subterráneo de la economía. 